\title{
Has frugivory influenced the macroecology and diversification of a tropical keystone plant family?
}

\author{
W. Daniel Kissling $\ddagger$ \\ ‡ University of Amsterdam, Amsterdam, Netherlands
}

Corresponding author: W. Daniel Kissling (wdkissling@gmail.com)

Reviewable v1

Received: 08 Jul 2017 | Published: 11 Jul 2017

Citation: Kissling WD (2017) Has frugivory influenced the macroecology and diversification of a tropical keystone plant family? Research Ideas and Outcomes 3: e14944. https://doi.org/10.3897/rio.3.e14944

\begin{abstract}
Seed dispersal by fruit-eating animals is a pivotal ecosystem function in tropical forests, but the role that frugivores have played in the biogeography and macroevolution of species-rich tropical plant families remains largely unexplored. This project investigates how frugivoryrelevant plant traits (e.g. fruit size, fruit color, fruit shape etc.) are distributed within the angiosperm family of palms (Arecaceae), how this relates to diversification rates, and whether and how it coincides with the global biogeographic distribution of vertebrate frugivores (birds, bats, primates, other frugivorous mammals) and their ecological traits (e.g. diet specialization, body size, flight ability, color vision etc.). Palms are particularly suitable because they are well studied, species-rich, characteristic of tropical rainforests, and dispersed by all groups of vertebrate seed dispersers. Using newly compiled data on species distributions and ecological traits in combination with phylogenies we will test (1) how fruit trait variability relates to palm phylogeny and other aspects of plant morphology (e.g. leaf size, plant height, growth form), (2) whether geographic variability in fruit traits correlates with geographic distributions of animal consumers and their traits, and (3) to what extent interaction-relevant plant traits are related to palm diversification rates. This combined macroecological and macroevolutionary approach allows novel insights into the global ecology and the evolution of a tropical keystone plant family. This is important for the conservation and sustainable management of tropical rainforests because palms are often key components of subsistence economies, ecosystem dynamics and carbon storage and therefore help to enhance nature's goods, benefits and services to humanity.
\end{abstract}




\section{Keywords}

Frugivory, macroevolution, macroecology, biogeography, plant-animal interactions

\section{List of participants}

\section{Research team}

- $\quad$ Renske Onstein (Postdoc, University of Amsterdam, Amsterdam, The Netherlands)

- W. Daniel Kissling (Associate Professor, University of Amsterdam, Amsterdam, The Netherlands)

- William J. Baker (Head of Comparative Plant and Fungal Biology, Royal Botanic Gardens, Kew, UK)

- Jens-Christian Svenning (Professor, Aarhus University, Denmark)

- Thomas L. P. Couvreur (Researcher, Institute of Research for Development, Marseille, France)

- $\quad$ Søren Faurby (Assistant Professor, University of Gothenburg, Göteborg, Sweden)

\section{Scientific background}

A pivotal ecosystem function in tropical forests is animal-mediated seed dispersal, with about $90 \%$ of tropical plant species requiring animals to disperse their seeds (Howe and Smallwood 1982). Frugivorous birds and mammals are the most diverse and important seed dispersers in tropical forests and are essential for forest structure and plant population dynamics by dispersing seeds to sites distant from the mother tree, to previously unoccupied sites, and to sites with suitable environmental conditions. Frugivore-mediated seed dispersal is thus crucial for vegetation structure, ecosystem dynamics, and plant responses to anthropogenic disturbances and environmental change because it affects plant colonization ability, gene flow, and the genetic structure of plant populations (Fleming and Kress 2013). Tropical rainforests are particularly sensitive to climate and land use change (Sala et al. 2000) and play an important role in the global carbon cycle because they store a large proportion of the world's carbon pool (Brown and Lugo 1982). Understanding the role of plant-frugivore interactions in ecosystem dynamics is thus crucial for the sustainable governance of our biological resources and the goods and services they provide to humanity (Sekercioglu 2006). This is recognized as a key priority not only by the scientific community (Cardinale et al. 2012) but also by several relevant policy bodies including the Convention on Biological Diversity (CBD) and its Aichi targets for 2020 (http:// www.cbd.int/sp/targets/). 
Studies of functional and interaction diversity are almost exclusively conducted at small spatial scales, and knowledge on multispecies interactions at macroecological scales is largely lacking (Kissling and Schleuning 2015). However, frugivores and their movement behaviors are important at broad spatial scales, e.g. via the frequency of long-distance dispersal events (Fleming and Kress 2013). This can potentially influence allopatric speciation of plants (the dominant speciation mode) through their effects on seed dispersal distances and the geographic pattern of seed rain (Fleming and Kress 2013). Specific traits of both plants (e.g. fruit size, fruit color, fruit shape, and understory/canopy growth form) and their dispersers (e.g. diet specialization, body size, flight ability, color vision etc.) can affect this plant-animal interaction. For instance, the relationship between fruit size and frugivore body size is of particularly importance (Burns and Lake 2009, Jordano 1995, Lord 2004) because frugivore body size correlates with gape width and sets the limits to the ingestion of fruits by relatively small-sized seed dispersers. It has been suggested that plant genera in regions with many large-bodied frugivores (e.g. mammals in Australia or Africa) have evolved larger seeds than their counterparts in regions where large-bodied frugivores are less dominant (e.g. no mammalian frugivores in New Zeeland, few largebodied frugivores in the Neotropics) (Mack 1993, Lord 2004). Similar trends can be observed for other morphological and chemical fruit traits (e.g. Dominy et al. 2003, Lomascolo et al. 2010, Voigt et al. 2004), but comprehensive biogeographic comparisons of fruit trait variation in relation to phylogeny and the geographic distribution of frugivores at large spatial scales are lacking.

\section{Aims, objectives and hypotheses}

The aim of this project is to understand the macroecology and diversification of a tropical plant family in relation to frugivory-relevant plant traits and the biogeographic distribution of vertebrate consumers (Fig. 1). The palm family (Arecaceae) is a good model system for understanding the ecology and evolution of tropical rainforests because (1) palms are representative of the tropical rainforest biome, (2) their biology, taxonomy and geographic distributions are well-documented, (3) comprehensive phylogenetic hypotheses are available, and (4) the historical timeframe coincides with that of the rainforest biome (Couvreur and Baker 2013, Eiserhardt et al. 2011). Palms are often hyper-dominant (ter Steege et al. 2013) and therefore also of key importance for ecosystem dynamics, forest structure and carbon storage. Moreover, palms are an attractive plant group for studying plant-frugivore interactions (e.g. Galetti et al. 2013, Jansen et al. 2012) and ideally suited to explore the global ecology of species interactions because they are species-rich (ca. 2500 species), globally distributed (pantropical), diverse in their ecological traits (e.g. fruit sizes, fruit colors, growth forms etc.), and attractive to a wide variety of animal seed dispersers, including all major groups of frugivorous vertebrates (birds, bats, primates, other mammals) (Dransfield et al. 2008, Fleming and Kress 2013, Zona and Henderson 1989). 


\section{(A) Fruit size of palms}

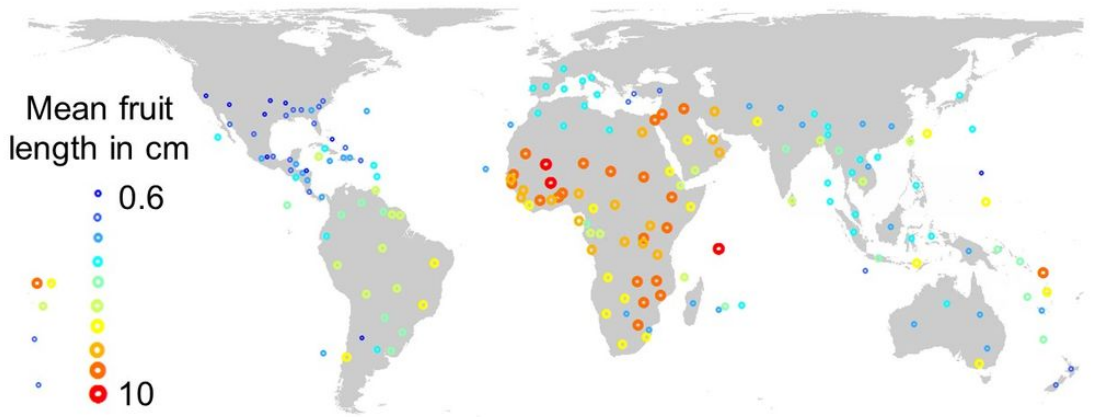

\section{(B) Body mass of consumers}

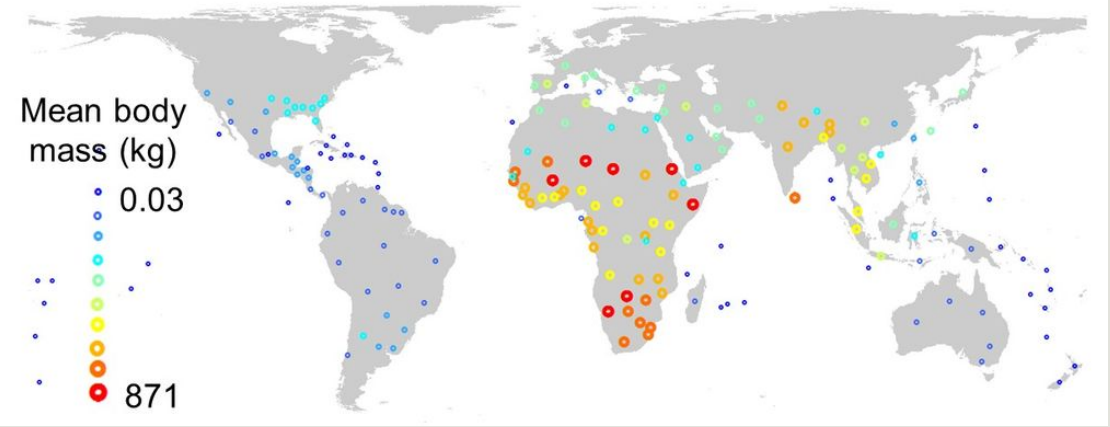

Figure 1. doi

Global functional trait distributions of palms $(n=2469)$ and frugivorous consumers $(n=3835$, incl. birds and mammals), showing large-scale co-variation between (a) palm fruit size (length in $\mathrm{cm}$ ) and (b) consumer body size (mass in $\mathrm{kg}$ ). Symbols are plotted for the mass centroids of geographic units ('botanical countries', TDWG level 3 units) and represent mean values across all species in a given unit. Values are calculated across a total of 29,032 species-level occurrences $(5,218$ for palms, 23,814 for consumers).

Using palms as a model system, the specific objectives of this project are:

1. to quantify the variability of fruit traits (e.g. fruit size, colour, shape) across a tropical plant family in relation to phylogeny and other aspects of plant morphology (e.g. leaf size, plant height, growth form, etc.)

2. to test how geographic variability in palm fruit traits is related to the macroecological and biogeographic distribution of avian and mammalian frugivores and their traits (e.g. body size, degree of fruit eating etc.)

3. to test whether macroevolutionary diversification rates of palms are related to fruit size or other interaction-relevant traits such as plant growth form (e.g. understory vs. canopy). 
These specific objectives were chosen because previous studies on plant-frugivore interactions allow to formulate a number of hypotheses about how the variability in fruit traits can be related to phylogeny, plant allometry, diversification, and geography or the biogeographic distribution of animal disperser. More specifically, the following hypotheses will be tested:

H1 ('allometric constraints hypothesis'): Fruit traits (e.g. size, shape, colour etc.) are non-randomly distributed across phylogeny because they are phylogenetically conserved (Jordano 1995; but see Stournaras et al. 2013) and because specific fruit traits (e.g. fruit size) do not evolve independently from other aspects of plant morphology such as leaf size, plant height or growth form (Herrera 2002, Herrera 1992). This could be interpreted as phylogenetic conservatism or adaptive divergence that is independent from seed dispersal agents ('allometric constraints'; Herrera 2002, Niklas 1994).

H2 ('consumer biogeography hypothesis'): Geographic variability in fruit traits (size, colour, shape) is correlated with the biogeographic distribution and trait variability of animal consumers (Fig. 1) because the evolution of fruit traits depends on the regional presenceabsence and commonness of frugivores and their traits (Dominy et al. 2003, Mack 1993, Lord 2004, Voigt et al. 2004). Specifically, it will be tested whether H2a: the mean and range of fruit sizes is larger in regions that have many large-bodied frugivores (Mack 1993) or larger variability in consumer body sizes (Burns and Lake 2009); H2b: the distribution of fruit colours coincides with the biogeographic occurrence and dominance of birds vs. mammals (Voigt et al. 2004) or the colour vision of primates (Dominy et al. 2003); and H2c: large fruits are more elongated than small fruits because gape size of animal dispersers could have influenced the evolution of fruit shape (Lord 2004).

H3 ('diversification rate hypothesis'): Fruit characteristics or other interaction-relevant traits have an influence on diversification rates (Fig. 2), especially via the frequency of longdistance dispersal events (Fleming and Kress 2013, Givnish 2010). The following hypotheses will be tested: H3a: Fruit size is negatively related to net diversification rates because high rates of long-distance dispersal by large-bodied frugivores should limit allopatric speciation of large-fruited plants due to high gene flow among plant populations (Fleming and Kress 2013). Hence, diversification (especially speciation) is higher in clades with small fruit sizes than for clades with large fruit sizes, particularly in regions where longdistance dispersal is challenging (e.g. island environments in Southeast Asia). Alternatively, long-distance dispersal and large geographical range sizes of large-fruited plants may decrease extinction rates and therefore increase net diversification rates (Goldberg et al. 2011). H3b: Tropical understory plants diversify more extensively than other plant growth forms because gene flow is restricted by short-distance dispersal of sedentary understory frugivores (Givnish 2010). This restricted dispersal (combined with occasional long-distance dispersal events) promotes the divergence of isolated plant populations and hence increases the probability of speciation (Fleming and Kress 2013). 


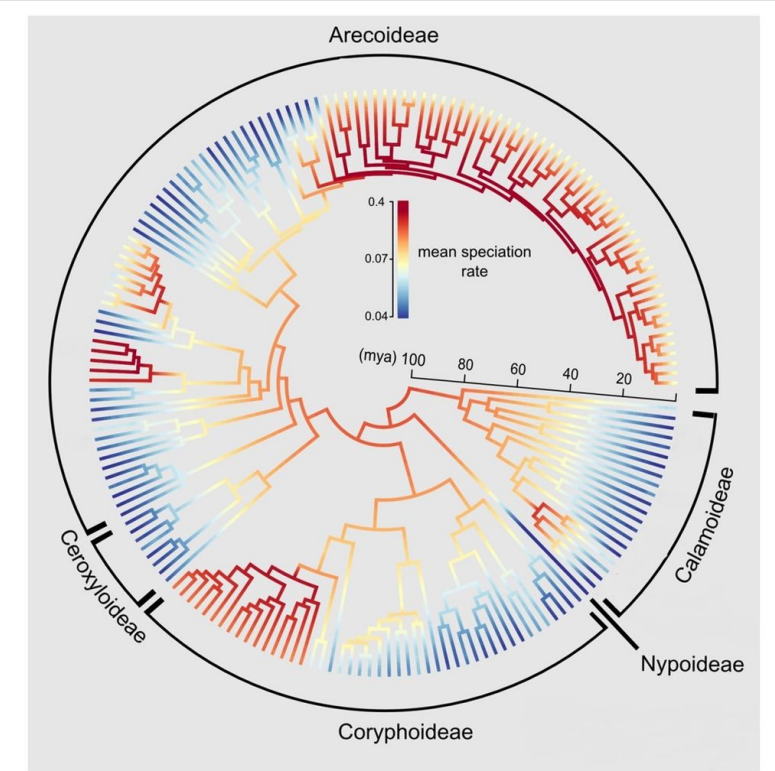

Figure 2. doi

Global diversification of palms. Branches are coloured by mean diversification rates across the time-calibrated generic-level phylogeny of palms estimated using Bayesian Analysis of Macroevolutionary Mixtures (BAMM).

\section{Impact}

The unprecedented and comprehensive assessment of interaction-relevant palm functional traits in relation to phylogeny, geography and animal consumers will shed new light on the evolution and biogeography of tropical rainforests. These findings will have important scientific impact by contributing to the overall assessment of what determines biodiversity (Pennisi 2005), especially in relation to the potential role of mutualistic plant-frugivore interactions. This will also be important for conservation and global change management because changes in climate and land-use might reshuffle biotic interactions across large spatial scales and we need to understand whether functional links between consumers and their resources are crucial (Kissling et al. 2012d, Wisz et al. 2013). Our approach of integrating macroevolutionary and macroecological approaches will be also innovative and promote further progress in merging the quantitative analytical tools in these research fields Jetz et al. 2012, Kissling et al. 2012b, Morlon 2014). We will also make an important step forward in advancing the newly emergent field of 'functional biogeography' (Violle et al. 2014) which bridges the often highly separated fields of ecology, evolution, and physical geography. Besides this scientific relevance, our research has societal impact because it contributes to the Aichi targets of the Convention on Biological Diversity (CBD). For instance, palms are often particularly abundant and dominant in tropical forests (ter Steege et al. 2013) and therefore represent a key component of ecosystem dynamics and carbon 
storage. Simple palm traits (e.g. stem height) allow to estimate palm biomass (Goodman et al. 2013) and our global palm trait dataset can therefore contribute to global carbon storage estimation (Aichi target 15 of CBD). Moreover, our research is relevant for the sustainable management of forest ecosystems (Aichi target 7 of CBD) because trait-dependent changes in plant-animal interactions (e.g. the defaunation and functional extinction of largebodied frugivores; Galetti et al. 2013) can have dramatic ecological and evolutionary consequences, including effects on diversity, ecosystem processes, phenology and genetic structure Galetti and Dirzo 2013. If fruit traits (e.g. size) are allometrically related to plant size (e.g. stem height), the functional extinction of frugivores can also influence ecosystem services such as carbon storage. Finally, palms are widely used in subsistence economies or traded in local, regional or international markets and therefore are of major economic importance (http://www.fp7-palms.org). A deeper understanding of the origin and functioning of palms and their interdependencies with other organisms will therefore help to contribute to enhancing the benefits, goods and services that palms provide to humanity (Aichi target 14 of CBD).

\section{Scientific approach}

We will use a range of quantitative analytical tools for macroecological and macroevolutionary inference with large datasets, including phylogenetic comparative analyses (Dodd et al. 1999, Jordano 1995, Onstein et al. 2014), phylogenetic regression (Barnagaud et al. 2014), advanced spatial modelling (Kissling and Carl 2008), and diversification rate analyses (Couvreur et al. 2015, Onstein et al. 2014). We thereby apply innovative informatics-based approaches to integrate phylogenetic, species distribution, and functional trait data with the aim of advancing our understanding of the role of frugivory in the macroevolution of palms. For phylogenetic data, we have access to a complete and time-calibrated genus-level phylogeny of palms (Couvreur et al. 2011), already used by us for diversification analyses (Baker and Couvreur 2013, Couvreur et al. 2015) and global community-level phylogenetics (Kissling et al. 2012b). We further have a new species-level phylogeny available using a super tree approach, with similarities to the bird supertree (Jetz et al. 2012) and based on the approach we recently published for all mammals (Faurby and Svenning 2015). Regarding species distribution data, we have an exceptional and unique global dataset (see preliminary data) covering all palms ( $>2500$ species) as well as all birds and all mammals ( $>15,000$ species). Range maps of birds and mammals (Kissling et al. 2009, Kissling et al. 2012a, Sandom et al. 2013, Barnagaud et al. 2014) will be intersected with palm distribution data as available from the exhaustive and authoritative World Checklist of Palms at the resolution of 'botanical countries' (Kissling et al. 2012c). The combined dataset includes all $>29,000$ occurrence records for palms and frugivorous vertebrates at this resolution. Regarding traits, we have compiled comprehensive trait datasets for both palms and frugivores (see preliminary data). This covers all relevant palm traits (e.g. fruit characteristics, leave sizes, stem heights etc.) as well as diet and body size information for all birds and mammals (Barnagaud et al. 2014, Kissling et al. 2009, Kissling et al. 2012a, Kissling et al. 2014, Sandom et al. 2013. Missing trait data is filled with hierarchical methods (e.g. Kissling et al. 2014, Shan et al. 2012). 
Hypothesis 1: For addressing $\mathrm{H} 1$ (allometric constraints and variation in fruit traits), we quantify variation in fruit traits (e.g. length, width, diameter, color, shape etc.) in relation to phylogeny and allometry (leaf size, stem height, stem diameter etc.) and test for correlated evolution. We will reconstruct ancestral states of traits on the phylogenetic tree to investigate the effects of topology and branch-length variation on results. We will further test for phylogenetic signal in traits using Pagel's $\lambda$ and Blomberg's $K$ (Blomberg et al. 2003, Pagel 1999) to indicate whether related species are more similar in traits than at random. Quantitative analyses will be based on phylogenetic comparative methods using 'BayesTraits', 'SIMMAP', and the 'geiger', 'phytools', 'caper', 'ape' or other similar R packages.

Hypothesis 2: We will implement novel co-occurrence analyses (Barnagaud et al. 2014, Villalobos et al. 2013) in which the structure of species assemblages (e.g. palm phylogenetic relatedness, variation in body sizes of co-occurring consumers, presence/ dominance of large-bodied or volant/non-volant species etc.) will be quantified across the geographic distribution of each individual palm species. This species-centred approach allows us to incorporate species distributional and phylogenetic information with ecological traits and environment (Barnagaud et al. 2014). Hence, we will link species-level information on functional traits of palms (e.g. fruit size [H3a], fruit colour [H3b], fruit shape $[\mathrm{H} 3 \mathrm{c}])$ to the phylogenetic structure of palm co-occurrences and the diversity and functional structure of bird and mammal assemblages. We will use ArcGIS and spatial and phylogenetic methods in R, using the packages 'spdep', 'picante', 'phylolm', 'OUwie' or other similar R packages.

Hypothesis 3: We will use the newly developed Bayesian Analysis of Macroevolutionary Mixtures (BAMM; Rabosky 2014) or similar tools to quantify time-varying diversification processes of palms in relation to fruit size ( $\mathrm{H} 2 \mathrm{a})$. The 'tip-rates' can then be related to mean (or variability) in fruit sizes and disperser traits (e.g. body size) using phylogenetic generalized least squares regression (Rabosky et al. 2013). We will further implement diversification analyses for binary traits (e.g. BiSSE or ClaSSE; Maddison et al. 2007; or newer methods if available; Goldberg and Igić 2012) to test whether lineages with understorey growth forms (binary trait: yes/no) have had faster speciation rates and/or lower extinction rates than lineages with non-understorey growth forms. To test whether biogeography plays an (additional) role in the diversification process, we will test whether diversification rates differ between geographical regions (e.g. Old World vs. New World, continents, botanical countries). The R packages 'BAMMtools', 'diversitree', 'ape', 'picante' etc. will allow these macroevolutionary analyses. We are also open to apply newer methods to estimate diversification rates if they become available. 


\section{Innovative aspects}

The project has a number of unique and innovative aspects:

- Using an unprecedented global dataset on functional plant-animal traits we explore for the first time the global trait (co-)variation in palms and frugivores, a keystone tropical plant-animal interaction. To our knowledge, this dataset is exceptional as there is no other large tropical plant group for which such a complete set of resources is available. Little work has been done on quantifying functional traits at a global scale in general, and on combining trait and distribution datasets of speciesrich plant and animal taxa involved in plant-frugivore interactions in particular. This will provide novel insights into the functioning of tropical ecosystems, especially into the role that mutualisms play for the origin and maintenance of tropical rainforests.

- To date, the world of macroecology and the world of macroevolution have largely operated separately. However, the great potential to combine macroecological with macroevolutionary approaches at large and temporal spatial scales has been recognized (e.g. Jetz et al. 2012, Morlon 2014, Kissling et al. 2012b). This offers a substantial step forward in advancing our knowledge on the drivers of biodiversity, incl. functional biogeography (Violle et al. 2014). We will use an integrative approach by taking advantage of cutting-edge developments in data availability, computing power and new software tools to address complex large-scale ecoevolutionary questions with informatics-based approaches. To date, nobody has applied this integrative approach to the study of plant-frugivore interactions worldwide.

- Palms are a typical and important component of tropical rainforests worldwide. For instance, six out of the ten most abundant trees in the Amazon are palms (ter Steege et al. 2013). Together with the availability of global datasets on species distributions, phylogeny and traits, the palm family offers a unique possibility to establish a worldwide model system for understanding the ecology and evolution of tropical rainforests and the transfer and recycling of biomass from primary producer diversity to other trophic levels (Cardinale et al. 2011). This is not only important from an scientific point of view, but also for the conservation and sustainable management of this highly threatened ecosystem, and the goods and services it provides to humanity.

\section{Preliminary data}

For palms, we have established a global dataset of traits covering fruit characteristics, leave size, stem height, stem diameter, climbing, and acaulescence (from herbaria, floras, monographs, botanical gardens etc.). The current dataset (February 2015, unpublished) has trait information for the majority of species (73-100\% coverage) and will be finalized in this project. Distribution data of all palms have been processed before (Couvreur et al. 2015, Kissling et al. 2012b, Kissling et al. 2012c), but will be updated with a new download 
(all scripts ready and available). The complete and time-calibrated genus-level phylogeny of palms is available (Couvreur et al. 2011) and has been used by us in backbone analyses with terminally unresolved clades of known diversity (Couvreur et al. 2015, Kissling et al. 2012b). A new maximally resolved palm phylogeny that covers all species with available genetic data will be available via collaborator Svenning. For animals, we have access to unprecedented amounts of species geographic and trait data for birds and mammals worldwide. This includes (i) species distribution data (range maps) for all birds (ca. 10,000) and all mammals (>5,000) worldwide; (ii) diet information (to define the degree of frugivory) for all birds (Kissling et al. 2009, Kissling et al. 2012a) and all mammals (Kissling et al. 2014); and (iii) body sizes for ca. $60 \%$ of all birds (Barnagaud et al. 2014) and ca. $70 \%$ of all mammal species (Sandom et al. 2013).

\section{Timetable of the project}

The timetable of the project is provided in Fig. 3.

\begin{tabular}{|l|c|c|c|c|c|c|}
\hline & \multicolumn{2}{c|}{ Year 1 } & \multicolumn{2}{c|}{ Year 2 } & \multicolumn{2}{c|}{ Year 3 } \\
\hline & $01-06$ & $06-12$ & $01-06$ & $06-12$ & $01-06$ & $06-12$ \\
\hline Finalizing palm trait dataset & & & & & & \\
\hline Analysis of allometrcy/variation in palm traits & & & & & & \\
\hline Analysis of palm-frugivore trait biogeography & & & & & & \\
\hline Analysis of palm traits and diversification & & & & & & \\
\hline Visits to other labs/co-supervisors & Kew & & Aarhus & & Montpellier & \\
\hline Knowledge utilization and outreach (see \#7.) & & Lisbon & & Lisbon & & EUNOPS \\
\hline Education/training & Course & & Course & & & \\
\hline Paper writing & Paper 1 & Paper 1 & Paper 2 & Paper 2 & Paper 3 & Paper 3 \\
\hline
\end{tabular}

Figure 3. doi

Overview of project timetable

\section{Scientific embedding of the proposed research}

The applicant Dr. W. Daniel Kissling (http://www.danielkissling.de) is an internationally wellknown macroecologist and biogeographer with an expertise in handling and analysis of large ecological and taxonomic datasets. In January 2014, he has been newly appointed as an Associate Professor (UHD) of Quantitative Biodiversity Science at the Institute for Biodiversity and Ecosystem Dynamics (IBED), University of Amsterdam (UvA). Dr. W. Daniel Kissling is currently establishing a new research group at IBED which aims at integrating large datasets of species distributions and ecological traits together with environmental data and phylogenies to better understand the distribution of life on Earth (the past, present, and future of biodiversity). Dr. W. Daniel Kissling currently coordinates the BSc course 'Biodiversity \& Global Change', contributes to the UvA special research cluster 'Global Ecology', and is the scientific coordinator and PI of the newly funded Horizon 2020 project on 'GLOBal Infrastructures for Supporting Biodiversity research (GLOBIS-B)' (2015-2018). Dr. W. Daniel Kissling is currently a (co-)supervisor of $5 \mathrm{PhD}$ students and 2 MSc students and he additionally collaborates in several large-scale 
biodiversity projects with postdocs, early- and late-career scientists from various countries, including Germany, Denmark, the Netherlands, Brazil, Colombia, New Zealand, the UK, and the USA. He was handling editor for the journal The Condor (2009-2010), is currently handling editor for Ecography and Journal of Biogeography, and has been appointed since 2014 to the organising committee of the Netherlands Annual Ecology Meeting (NAEM). Dr. W. Daniel Kissling has published multiple scientific papers in both multi-disciplinary scientific journals (e.g. PNAS, Proc. Roy. Soc. B, Phil. Trans. Roy. Soc B) as well as ecological high-impact journals (e.g. Biol. Rev., Ecol. Lett., Ecology, Glob Ecol. Biogeogr., J. Biogeogr., Ecography, Glob. Change Biol., etc.). He has obtained several grants (totalling ca. 2 Mio EUR) including the prestigious 'Steno' stipend from the Danish Council for Independent Research | Natural Sciences (similar to the Dutch VENI personal grant). Since his postdoc (2010-2011) and subsequent Assistant Professorship (2012-2013) at Aarhus University (Denmark), he has collaborated closely with three international collaborators mentioned in this proposal. Prof. dr. Jens-Christian Svenning at Aarhus University (Denmark) is an international leader in plant biogeography and has successfully established a highly productive ecoinformatics research lab with a focus on plants (including palms) and mammals. Dr. William J. Baker, Head of Comparative Plant and Fungal Biology at the Royal Botanic Gardens, Kew (UK), heads the world's leading research group in global systematics and taxonomy of palms. Dr. Thomas L.P. Couvreur, researcher at the Institut de Recherche pour le Developpement (IRD) in Montpellier, France, is internationally known for his work on macroevolution of tropical plants, especially palms and their role for understanding the evolution of tropical rain forests. This fruitful collaboration has already resulted in several joined publications in high impact journals such as PNAS, Glob Ecology \& Biogeography, Ecology, Ecology Letters, and Frontiers in Genetics. Together, the members involved in the proposed research cover a broad range of methods, experience and expertise, which will guarantee the successful implementation of the proposed research.

\section{Knowledge utilisation}

To provide the knowledge of palm traits to beneficiaries, we will collaborate with Bertrand Duval, the developer of Palmworld.org, an online platform to share detailed information about palms with non-scientific people in a playful and modern way. Palmworld is available for free on a website (http://www.palmworld.org/) as well as an iPhone/iPad App in the Apple Store (Android devices are included soon). The App has been downloaded by almost 3000 people and knowledge utilization currently amounts to 30-40 distinct people every day, totalling $>13,000$ accessions annually across the whole world ( $>180$ countries). Beneficiaries include horticulturists, palm growers, field biologists, taxonomists, conservation managers, staff from botanical gardens, ethno-botanists, policy makers, people working in biotechnology, genomics and agronomy, and the general public. We will implement the species-level information about palms into Palmworld which will allow palm knowledge to be accessible in an easy and attractive format to a wide (non-scientific) audience. 
In addition to providing palm trait data in Palmworld to stakeholders and the general public, the dataset will be made available to scientific research via an open-access repository. This follows the suggestions from the "datamanagementbeleid" of the NWO (letter from 9 December 2014). The proposed research further follows the standards in biodiversity informatics for accessibility and documentation of data (Hardisty et al. 2013).

\section{Acknowledgements}

Many thanks to Willem Bouten, Renske E. Onstein, William J. Baker, Jens-Christian Svenning, Thomas L. P. Couvreur and Peter H. van Tienderen for support and discussion during writing this grant proposal, and three anonymous referees for their feedback and positive evaluation.

\section{Funding program}

Open Programme (earth and life sciences) of the Netherlands Organisation for Scientific Research (NWO grant 824.15.007).

\section{References}

- $\quad$ Baker W, Couvreur TP (2013) Global biogeography and diversification of palms sheds light on the evolution of tropical lineages. I. Historical biogeography. Journal of Biogeography 40 (2): 274-285. https://doi.org/10.1111/j.1365-2699.2012.02795.x

- Barnagaud JY, Kissling WD, Sandel B, Eiserhardt WL, Sekercioglu CH, Enquist BJ, Tsirogiannis C, Svenning J-C (2014) Ecological traits influence the phylogenetic structure of bird species co-occurrences worldwide. Ecology Letters 17 (7): 811-820. https://doi.org/10.1111/ele.12285

- Blomberg S, Garland T, Ives A (2003) Testing for phylogenetic signal in comparative data: behavioural traits are more labile. Evolution 57 (4): 717-745. https:// doi.org/10.1111/i.0014-3820.2003.tb00285.x

- $\quad$ Brown S, Lugo A (1982) The storage and production of organic matter in tropical forests and their role in the global carbon cycle. Biotropica 14 (3): 161-187. https:// doi.org/10.2307/2388024

- $\quad$ Burns KC, Lake B (2009) Fruit-frugivore interactions in two southern hemisphere forests: allometry, phylogeny and body size. Oikos 118 (12): 1901-1907. https:// doi.org/10.1111/j.1600-0706.2009.17661.x

- Cardinale B, Matulich K, Hooper D, Byrnes J, Duffy E, Gamfeldt L, Balvanera P, O'Connor M, Gonzalez A (2011) The functional role of producer diversity in ecosystems. Am. J. Bot. 98 (3): 572-592. https://doi.org/10.3732/ajb.1000364

- Cardinale B, Duffy JE, Gonzalez A, Hooper D, Perrings C, Venail P, Narwani A, Mace G, Tilman D, Wardle D, Kinzig A, Daily G, Loreau M, Grace J, Larigauderie A, Srivastava D, Naeem S (2012) Biodiversity loss and its impact on humanity. Nature 486 (7401): 59-67. https://doi.org/10.1038/nature11148 
- $\quad$ Couvreur T, Baker W (2013) Tropical rain forest evolution: palms as a model group. BMC Biology 11 (1): . URL: http://www.biomedcentral.com/1741-7007/11/48

- $\quad$ Couvreur TP, Forest F, Baker W (2011) Origin and global diversification patterns of tropical rain forests: inferences from a complete genus-level phylogeny of palms. BMC Biology 9 (1): 44. https://doi.org/10.1186/1741-7007-9-44

- Couvreur TP, Kissling WD, Condamine F, Svenning J, Rowe N, Baker W (2015) Global diversification of a tropical plant growth form: environmental correlates and historical contingencies in climbing palms. Frontiers in Genetics 5 https://doi.org/10.3389/ fgene.2014.00452

- Dodd ME, Silvertown J, Chase MW (1999) Phylogenetic analysis of trait evolution and species diversity variation among angiosperm families. Evolution 53 (3): 732-744. https://doi.org/10.2307/2640713

- Dominy NJ, Svenning JC, Li WH (2003) Historical contingency in the evolution of primate color vision. Journal of Human Evolution 44 (1): 25-45. https://doi.org/10.1016/ s0047-2484(02)00167-7

- $\quad$ Dransfield J, Uhl NW, Asmussen CB, Baker WJ, Harley MM, Lewis CE (2008) Genera palmarum - the evolution and classification of palms. Royal Botanical Gardens, Kew.

- $\quad$ Eiserhardt W, Svenning J, Kissling WD, Balslev H (2011) Geographical ecology of the palms (Arecaceae): determinants of diversity and distributions across spatial scales. Annals of Botany 108 (8): 1391-1416. https://doi.org/10.1093/aob/mcr146

- $\quad$ Faurby S, Svenning J (2015) A species-level phylogeny of all extant and late Quaternary extinct mammals using a novel heuristic-hierarchical Bayesian approach. Molecular Phylogenetics and Evolution 84: 14-26. https://doi.org/10.1016/j.ympev.2014.11.001

- $\quad$ Fleming TH, Kress WJ (2013) The ornaments of life: coevolution and conservation in the tropics. Chicago University Press, Chicago.

- Galetti M, Dirzo R (2013) Ecological and evolutionary consequences of living in a defaunated world. Biological Conservation 163: 1-6. https://doi.org/10.1016/ j.biocon.2013.04.020

- Galetti M, Guevara R, Côrtes M, Fadini R, Von Matter S, Leite A, Labecca F, Ribeiro T, Carvalho C, Collevatti R, Pires M, Guimarães P, Brancalion P, Ribeiro M, Jordano P (2013) Functional extinction of birds drives rapid evolutionary changes in seed size. Science 340 (6136): 1086-1090. https://doi.org/10.1126/science.1233774

- Givnish T (2010) Ecology of plant speciation. Taxon 59 (5): 1326-1366. URL: http:// www.ingentaconnect.com/content/iapt/tax/2010/00000059/00000005/art00003

- Goldberg E, Igić B (2012) Tempo and mode in plant breeding system evolution. Evolution 66 (12): 3701-3709. https://doi.org/10.1111/j.1558-5646.2012.01730.x

- Goldberg E, Lancaster L, Ree R (2011) Phylogenetic inference of reciprocal effects between geographic range evolution and diversification. Systematic Biology 60 (4): 451-465. https://doi.org/10.1093/sysbio/syr046

- Goodman R, Phillips O, del Castillo Torres D, Freitas L, Tapia Cortese S, Monteagudo A, Baker T (2013) Amazon palm biomass and allometry. Forest Ecology and Management 310: 994-1004. https://doi.org/10.1016/j.foreco.2013.09.045

- Hardisty A, Roberts D, Informatics Community ,TB (2013) A decadal view of biodiversity informatics: challenges and priorities. BMC Ecology 13 (1): . URL: http:// www.biomedcentral.com/1472-6785/13/16 
- Herrera C (2002) Correlated evolution of fruit and leaf size in bird-dispersed plants: species-level variance in fruit traits explained a bit further? Oikos 97 (3): 426-432. https://doi.org/10.1034/j.1600-0706.2002.970312.x

- Herrera CM (1992) Interspecific variation in fruit shape - allometry, phylogeny, and adaptation to dispersal agents. Ecology 73 (5): 1832-1841. https:// doi.org/10.2307/1940034

- Howe HF, Smallwood J (1982) Ecology of seed dispersal. Annual Review of Ecology and Systematics 13: 201-228. https://doi.org/10.1146/annurev.es.13.110182.001221

- Jansen P, Hirsch B, Emsens W, Zamora-Gutierrez V, Wikelski M, Kays R (2012) Thieving rodents as substitute dispersers of megafaunal seeds. Proceedings of the National Academy of Sciences 109 (31): 12610-12615. https://doi.org/10.1073/ pnas. 1205184109

- Jetz W, Thomas GH, Joy JB, Hartmann K, Mooers AO (2012) The global diversity of birds in space and time. Nature 491 (7424): 444-448. https://doi.org/10.1038/ nature11631

- Jordano P (1995) Angiosperm fleshy fruits and seed dispersers - a comparative analysis of adaptation and constraints in plant-animal interactions. American Naturalist 145 (2): 163-191. https://doi.org/10.1086/285735

- Kissling WD, Carl G (2008) Spatial autocorrelation and the selection of simultaneous autoregressive models. Global Ecology and Biogeography 17 (1): 59-71. https:// doi.org/10.1111/j.1466-8238.2007.00334.x

- Kissling WD, Schleuning M (2015) Multispecies interactions across trophic levels at macroscales: retrospective and future directions. Ecography 38 (4): 346-357. https:// doi.org/10.1111/ecog.00819

- Kissling WD, Böhning-Gaese K, Jetz W (2009) The global distribution of frugivory in birds. Global Ecology and Biogeography 18 (2): 150-162. https://doi.org/10.1111/ j.1466-8238.2008.00431.x

- Kissling WD, Sekercioglu C, Jetz W (2012a) Bird dietary guild richness across latitudes, environments and biogeographic regions. Global Ecology and Biogeography 21 (3): 328-340. https://doi.org/10.1111/1.1466-8238.2011.00679.x

- $\quad$ Kissling WD, Eiserhardt W, Baker W, Borchsenius F, Couvreur TP, Balslev H, Svenning $J(2012 b)$ Cenozoic imprints on the phylogenetic structure of palm species assemblages worldwide. Proceedings of the National Academy of Sciences of the United States of America 109 (19): 7379-7384. https://doi.org/10.1073/ pnas.1120467109

- Kissling WD, Baker W, Balslev H, Barfod A, Borchsenius F, Dransfield J, Govaerts R, Svenning J (2012c) Quaternary and pre-Quaternary historical legacies in the global distribution of a major tropical plant lineage. Global Ecology and Biogeography 21 (9): 909-921. https://doi.org/10.1111//.1466-8238.2011.00728.x

- Kissling WD, Dalby L, Fløjgaard C, Lenoir J, Sandel B, Sandom C, Trøjelsgaard K, Svenning J (2014) Establishing macroecological trait datasets: digitalization, extrapolation, and validation of diet preferences in terrestrial mammals worldwide. Ecology and Evolution 4 (14): 2913-2930. https://doi.org/10.1002/ece3.1136

- Kissling WD, Dormann C, Groeneveld J, Hickler T, Kühn I, Mclnerny G, Montoya J, Römermann C, Schiffers K, Schurr F, Singer A, Svenning J, Zimmermann N, O'Hara R (2012) Towards novel approaches to modelling biotic interactions in multispecies 
assemblages at large spatial extents. Journal of Biogeography 39 (12): 2163-2178. https://doi.org/10.1111/j.1365-2699.2011.02663.x

- $\quad$ Lomascolo S, Levey D, Kimball R, Bolker B, Alborn H (2010) Dispersers shape fruit diversity in Ficus (Moraceae). Proceedings of the National Academy of Sciences 107 (33): 14668-14672. https://doi.org/10.1073/pnas.1008773107

- Lord JM (2004) Frugivore gape size and the evolution of fruit size and shape in southern hemisphere floras. Austral Ecology 29 (4): 430-436. https://doi.org/10.1111/ j.1442-9993.2004.01382.x

- Mack AL (1993) The sizes of vertebrate-dispersed fruits - a Netropical-Paleotropical comparison. American Naturalist 142 (5): 840-856. https://doi.org/10.1086/285575

- Maddison W, Midford P, Otto S (2007) Estimating a binary character's effect on speciation and extinction. Systematic Biology 56 (5): 701-710. https:// doi.org/10.1080/10635150701607033

- Morlon H (2014) Phylogenetic approaches for studying diversification. Ecology Letters 17 (4): 508-525. https://doi.org/10.1111/ele.12251

- $\quad$ Niklas K (1994) Plant allometry - the scaling of form and process. University of Chicago Press, Chicago and London.

- Onstein R, Carter R, Xing Y, Linder HP (2014) Diversification rate shifts in the Cape Floristic Region: The right traits in the right place at the right time. Perspectives in Plant Ecology Evolution and Systematics 16 (6): 331-340. https://doi.org/10.1016/ j.ppees.2014.08.002

- $\quad$ Pagel M (1999) Inferring the historical patterns of biological evolution. Nature 401 (6756): 877-884. https://doi.org/10.1038/44766

- Pennisi E (2005) What determines species diversity. Science 309 (5731): 90-90. https:// doi.org/10.1126/science.309.5731.90

- Rabosky D (2014) Automatic detection of key innovations, rate shifts, and diversitydependence on phylogenetic trees. Plos One 9 (2): . https://doi.org/10.1371/ journal.pone.0089543

- $\quad$ Rabosky D, Santini F, Eastman J, Smith S, Sidlauskas B, Chang J, Alfaro M (2013) Rates of speciation and morphological evolution are correlated across the largest vertebrate radiation. Nat Commun $4 \mathrm{https} / / / \mathrm{doi} .0 \mathrm{rg} / 10.1038 / \mathrm{ncomms} 2958$

- Sala OE, Chapin FS, Armesto JJ, Berlow E, Bloomfield J, Dirzo R, Huber-Sanwald E, Huenneke LF, Jackson RB, Kinzig A, Leemans R, Lodge DM, Mooney HA, Oesterheld M, Poff NL, Sykes MT, Walker BH, Walker M, Wall DH (2000) Biodiversity - Global biodiversity scenarios for the year 2100. Science 287 (5459): 1770-1774. URL: $: / / 000085775300030$

- $\quad$ Sandom C, Dalby L, Fløjgaard C, Kissling WD, Lenoir J, Sandel B, Trøjelsgaard K, Ejrnæs R, Svenning J (2013) Mammal predator and prey species richness are strongly linked at macroscales. Ecology 94 (5): 1112-1122. https://doi.org/10.1890/12-1342.1

- Sekercioglu CH (2006) Increasing awareness of avian ecological function. Trends in Ecology \& Evolution 21 (8): 464-471. https://doi.org/10.1016/j.tree.2006.05.007

- Shan H, Kattge J, Reich PB, Banerjee A, Schrodt F, Reichstein M (2012) Gap filling in the plant kingdom - trait prediction using hierarchical probabilistic matrix factorization. Proceedings of the 29 th International Conference on Machine Learning (ICML-12) 1303-1310.

- Stournaras K, Lo E, Böhning-Gaese K, Cazetta E, Matthias Dehling D, Schleuning M, Stoddard MC, Donoghue M, Prum R, Martin Schaefer H (2013) How colorful are fruits? 
Limited color diversity in fleshy fruits on local and global scales. New Phytologist 198 (2): 617-629. https://doi.org/10.1111/nph.12157

- $\quad$ ter Steege H, Pitman NA, Sabatier D, Baraloto C, Salomão R, Guevara JE, Phillips O, Castilho C, Magnusson W, Molino J, Monteagudo A, Núñez Vargas P, Montero JC, Feldpausch T, Coronado EH, Killeen T, Mostacedo B, Vasquez R, Assis R, Terborgh J, Wittmann F, Andrade A, Laurance W, Laurance SW, Marimon B, Marimon B, Guimarães Vieira IC, Amaral IL, Brienen R, Castellanos H, Cárdenas López D, Duivenvoorden J, Mogollón H, Matos FDdA, Dávila N, García-Villacorta R, Stevenson Diaz PR, Costa F, Emilio T, Levis C, Schietti J, Souza P, Alonso A, Dallmeier F, Montoya AJD, Fernandez Piedade MT, Araujo-Murakami A, Arroyo L, Gribel R, Fine PA, Peres C, Toledo M, Gerardo A. A, Baker T, Cerón C, Engel J, Henkel T, Maas P, Petronelli P, Stropp J, Zartman CE, Daly D, Neill D, Silveira M, Paredes MR, Chave J, Lima Filho DdA, Jørgensen PM, Fuentes A, Schöngart J, Cornejo Valverde F, Di Fiore A, Jimenez E, Peñuela Mora MC, Phillips JF, Rivas G, van Andel T, von Hildebrand P, Hoffman B, Zent E, Malhi Y, Prieto A, Rudas A, Ruschell A, Silva N, Vos V, Zent S, Oliveira A, Schutz AC, Gonzales T, Trindade Nascimento M, Ramirez-Angulo H, Sierra R, Tirado M, Umaña Medina MN, van der Heijden G, Vela CA, Vilanova Torre E, Vriesendorp C, Wang O, Young K, Baider C, Balslev H, Ferreira C, Mesones I, Torres-Lezama A, Urrego Giraldo LE, Zagt R, Alexiades M, Hernandez L, Huamantupa-Chuquimaco I, Milliken W, Palacios Cuenca W, Pauletto D, Valderrama Sandoval E, Valenzuela Gamarra L, Dexter K, Feeley K, Lopez-Gonzalez G, Silman M (2013) Hyperdominance in the Amazonian tree flora. Science 342 (6156): . https://doi.org/10.1126/

\section{science.1243092}

- Villalobos F, Rangel T, Diniz-Filho J (2013) Phylogenetic fields of species: cross-species patterns of phylogenetic structure and geographical coexistence. Proceedings of the Royal Society B: Biological Sciences 280 (1756): . https://doi.org/10.1098/

rspb.2012.2570

- Violle C, Reich P, Pacala S, Enquist B, Kattge J (2014) The emergence and promise of functional biogeography. Proceedings of the National Academy of Sciences 111 (38): 13690-13696. https://doi.org/10.1073/pnas.1415442111

- Voigt FA, Bleher B, Fietz J, Ganzhorn JU, Schwab D, Böhning-Gaese K (2004) A comparison of morphological and chemical fruit traits between two sites with different frugivore assemblages. Oecologia 141 (1): 94-104. https://doi.org/10.1007/ s00442-004-1654-8

- Wisz MS, Pottier J, Kissling WD, Pellissier L, Lenoir J, Damgaard C, Dormann C, Forchhammer M, Grytnes J, Guisan A, Heikkinen R, Høye T, Kühn I, Luoto M, Maiorano L, Nilsson M, Normand S, Öckinger E, Schmidt N, Termansen M, Timmermann A, Wardle D, Aastrup P, Svenning J (2013) The role of biotic interactions in shaping distributions and realised assemblages of species: implications for species distribution modelling. Biological Reviews 88 (1): 15-30. https://doi.org/10.1111/ j.1469-185X.2012.00235.X

- Zona S, Henderson A (1989) A review of animal mediated seed dispersal of palms. Selbyana 11: 6-21. 